Provided for non-commercial research and educational use only. Not for reproduction or distribution or commercial use.

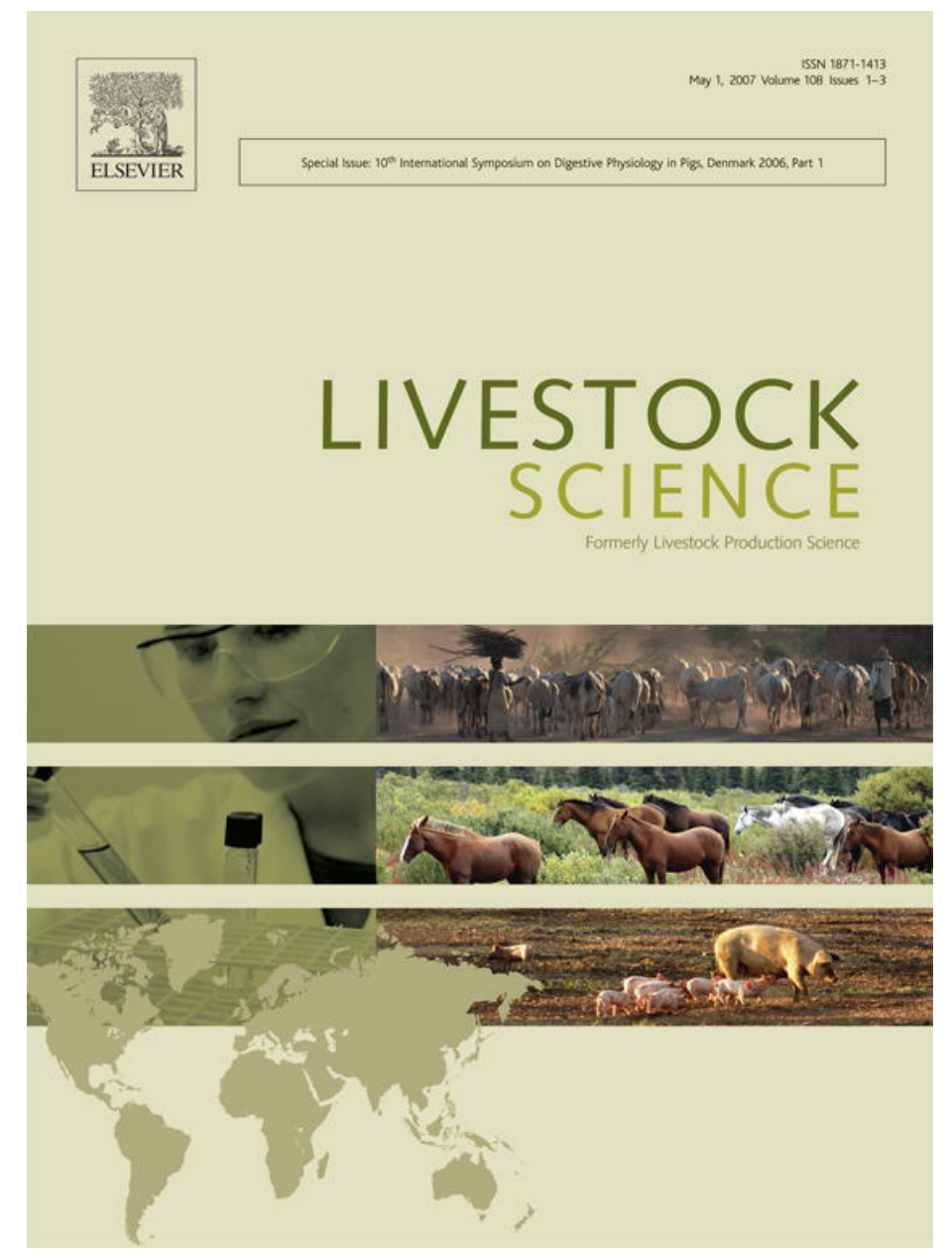

This article was originally published in a journal published by Elsevier, and the attached copy is provided by Elsevier for the author's benefit and for the benefit of the author's institution, for non-commercial research and educational use including without limitation use in instruction at your institution, sending it to specific colleagues that you know, and providing a copy to your institution's administrator.

All other uses, reproduction and distribution, including without limitation commercial reprints, selling or licensing copies or access,

or posting on open internet sites, your personal or institution's website or repository, are prohibited. For exceptions, permission may be sought for such use through Elsevier's permissions site at: 


\title{
Effect of prebiotic or probiotic supplementation and ileo rectal anastomosis on intestinal morphology of weaned piglets 2 ?
}

\author{
M.C. Marinho ${ }^{\text {a }, ~ M . A . ~ P i n h o ~}{ }^{\text {b }}$, R.D. Mascarenhas ${ }^{\text {c }, ~ F . C . ~ S i l v a ~}{ }^{\text {d }}$, M.M. Lordelo e \\ L.F. Cunha ${ }^{\mathrm{e}}$, J.P.B. Freire ${ }^{\mathrm{e}, *}$ \\ ${ }^{a}$ Escola Superior Agrária de Castelo Branco, Apartado 119, 6000-909 Castelo Branco, Portugal \\ ${ }^{\mathrm{b}}$ Universidade Técnica de Lisboa, Faculdade de Medicina Veterinária, Alto da Ajuda, 1300-477 Lisboa, Portugal \\ ${ }^{\mathrm{c}}$ Estação Zootécnica Nacional, Fonte Boa, 2000-763 Vale de Santarém, Portugal \\ ${ }^{\mathrm{d}}$ Universidade de Évora, Herdade da Mitra, Valverde 7000 Évora, Portugal \\ e Universidade Técnica de Lisboa, Instituto Superior de Agronomia, Tapada da Ajuda, 1340-017 Lisboa, Portugal
}

\begin{abstract}
Forty eight 21 days old piglets were used to compare the effect of prebiotic or probiotic supplementation and ileo rectal anastomosis on the morphology of the small intestine. Half of the piglets were maintained intact and the other half was subjected to an ileo rectal anastomosis (IRA). Each group of piglets received one of the following diets: 1) basal diet (C), 2) basal diet supplemented with a Xylo-oligosaccharide (XOS), 3) basal diet supplemented with a Saccharomyces cerevisiae (SC) and 4) basal diet supplemented with XOS and SC. Villus height was greatest with XOS and with XOS + SC, only in the ileum, as compared to controls. In the duodenum, crypt width was highest in the control group, but no significant differences were found in the jejunum and ileum. The IRA piglets had longer villi in the jejunum and shorter villi in the ileum. The crypt depth was greater in the duodenum and in the ileum of IRA piglets. Villus height/crypt depth was lower in the duodenum and in the ileum, in the IRA piglets. In conclusion, the XOS, but not the SC, moderately modified the intestinal morphology. The IRA modified the intestinal villus and crypt architecture but its consequence on the absorption of nutrients needs to be investigated.
\end{abstract}

(C) 2007 Elsevier B.V. All rights reserved.

Keywords: Piglets; Xylo-oligosaccharides; Anastomosis; Villus; Crypt

\section{Introduction}

According to Collins and Gibson (1999) the potential health benefits of probiotic and prebiotic administration

\footnotetext{
th This paper is part of the special issue entitled "Digestive Physiology in Pigs" guest edited by José Adalberto Fernández, Mette Skou Hedemann, Bent Borg Jensen, Henry Jørgensen, Knud Erik Bach Knudsen and Helle Nygaard Lærke.

* Corresponding author. Tel.: +351 213653408, fax: +351 213630734 .

E-mail address: jpfreire@isa.utl.pt (J.P.B. Freire).
}

include improvement of digestion, stimulation of gastrointestinal immunity and increased natural resistance to infectious enteric disease. The most prevalent probiotics studied in swine diets include Saccharomyces cerevisiae. The major effect of this probiotic is located in the small intestine of monogastric animals, involving stimulation of brush border disaccharidases (Buts et al., 1994), antiadhesive effect against pathogens (Line et al., 1998), toxin action inhibition (Castagliulo et al., 1996) and antagonism against pathogenic micro-organisms (Ducluzeau and Besaada, 1982). Xylo-oligosaccharides (XOS) are 
naturally present in different by-products. They can reach the hindgut of monogastric animals and support the growth of beneficial bifidobacteria (Maxwell et al., 2004). Short chain fatty acids (SCFA) are end products of the intestinal microbial fermentation of oligosaccharides. Among SCFA, butyrate is particularly important for the structure and the function of the epithelial cells of intestinal mucosa.

The ileo-rectal anastomosis (IRA) is used to collect ileal digesta (Fuller, 1991), but little research has been conducted to determine the short-term effects of the IRA on intestinal morphology. Nevertheless, Salgado et al. (2002) reported duodenal crypts elongation and jejunal villi enlargement in anastomosed pigs, 3 weeks after surgery.

The aim of this work is to evaluate the effect of XOS or Saccharomyces cerevisiae supplementation and ileo rectal anastomosis on intestinal morphology of weaned piglets.

\section{Materials and methods}

Forty eight male piglets, weaned at 21 days of age, were used. Half of the piglets were maintained intact and the other half was subjected to an ileo-rectal anastomo- sis (IRA) and left for recovery during 2 weeks. After the recovery period, the intact and the IRA piglets were divided in four groups of 12 piglets each (six intact and six anastomosed). During a period of 3 weeks each group of piglets received one of the following diets: 1) basal diet (C), 2) basal diet supplemented with a XOS $\left(20 \mathrm{~g} \mathrm{~kg}^{-1}\right)$, 3) basal diet supplemented with a SC $\left(6 \times 10^{8} \mathrm{CFU} \mathrm{kg^{-1 } )}\right.$ and 4) basal diet supplemented with XOS and SC (XOS-SC). At the end of the experimental period the piglets were slaughtered, duodenal and jejunal samples were taken approximately $10 \mathrm{~cm}$ and $5.5 \mathrm{~m}$ below the pylorus. Ileum samples were collected from $60 \mathrm{~cm}$ above the ileum-cecal valve. The height of the villi and the depth of the crypts were measured with a microscope with an ocular micrometer. Reported mean value for each animal was based on 20 measurements. Data were subjected to analyses of variance using the GLM procedure of SAS (1989), the effects of the diet (D), the IRA and their interactions have been tested.

\section{Results}

Morphology results of the duodenum, jejunum and ileum are presented in Table 1. The addition of XOS or

Table 1

Effect of XOS or SC supplementation and ileo rectal anastomosis (IRA) on the intestinal morphology

\begin{tabular}{|c|c|c|c|c|c|c|c|c|c|}
\hline & \multicolumn{4}{|l|}{ Diets } & \multicolumn{5}{|l|}{ IRA } \\
\hline & $\mathrm{C}$ & XOS & $\mathrm{SC}$ & $\mathrm{XOS}+\mathrm{SC}$ & - & + & $\mathrm{D}$ & $\mathrm{A}$ & $\mathrm{RSD}^{(1)}$ \\
\hline \multicolumn{10}{|c|}{ Villus height $(\mu m)$} \\
\hline Duodenum & 395 & 395 & 400 & 437 & 399 & 415 & NS & NS & 51 \\
\hline Jejunum & 385 & 398 & 425 & 406 & 386 & 422 & NS & $* *$ & 42 \\
\hline Ileum & $327^{\mathrm{a}}$ & $374^{\mathrm{b}}$ & $359^{\mathrm{ab}}$ & $367^{\mathrm{b}}$ & 370 & 343 & $*$ & $*$ & 43 \\
\hline \multicolumn{10}{|c|}{ Villus width $(\mu \mathrm{m})$} \\
\hline Duodenum & 205 & 195 & 197 & 187 & 199 & 193 & NS & NS & 24 \\
\hline Jejunum & 165 & 155 & 155 & 158 & 159 & 158 & NS & NS & 14 \\
\hline Ileum & 166 & 173 & 165 & 166 & 170 & 165 & NS & NS & 13 \\
\hline \multicolumn{10}{|c|}{ Crypt depth $(\mu m)$} \\
\hline Duodenum & 287 & 296 & 285 & 309 & 255 & 334 & NS & $* *$ & 39 \\
\hline Jejunum & 243 & 228 & 228 & 235 & 229 & 237 & NS & NS & 26 \\
\hline Ileum & 222 & 217 & 223 & 214 & 210 & 228 & NS & $*$ & 24 \\
\hline \multicolumn{10}{|c|}{ Crypt width $(\mu m)$} \\
\hline Duodenum & $68^{a}$ & $62^{\mathrm{b}}$ & $62^{\mathrm{b}}$ & $61^{\mathrm{b}}$ & 65 & 61 & $*$ & $*$ & 6.4 \\
\hline Jejunum & 58 & 61 & 59 & 60 & 60 & 59 & NS & NS & 4.0 \\
\hline Ileum & 58 & 58 & 58 & 58 & 57 & 59 & NS & NS & 3.9 \\
\hline \multicolumn{10}{|c|}{ Villus height/crypt depth } \\
\hline Duodenum & 1.43 & 1.38 & 1.42 & 1.47 & 1.59 & 1.25 & NS & $* * *$ & 0.23 \\
\hline Jejunum & 1.61 & 1.76 & 1.88 & 1.74 & 1.71 & 1.79 & NS & NS & 0.25 \\
\hline Ileum & 1.50 & 1.74 & 1.62 & 1.74 & 1.78 & 1.53 & NS & $* *$ & 0.26 \\
\hline
\end{tabular}

${ }^{(1)}$ Effects: D: diet; A: ileo rectal anastomosis; NS: Not significant; $* P<0.05 ; * * P<0.01 ; * * * P<0.001$. For all the variables, the interaction DxA: NS. Values with different letters in the same row differ significantly at $P<0.05$. Residual standard deviation. 
SC had no significant effects on villi width, crypts depth and villus/crypt ratio. Villus height in the ileum was greatest $(P<0.05)$ with XOS and with XOS-SC, as compared to controls. In the duodenum, crypt width was larger in the control group $(P<0.05)$, but no significant differences were found in the jejunum and ileum. The IRA did not significantly affect villus width. However, villi height was longer in the jejunum $(P<0.01)$ and shorter in the ileum $(P<0.05)$ of IRA piglets. The crypt depth was greater in the duodenum $(P<0.001)$ and in the ileum $(P<0.05)$, and the crypt width was smaller $(P<0.05)$ only in the duodenum of IRA piglets. The villus height/crypt depth ratio was lower in the duodenum $(P<0.001)$ and in the ileum $(P<0.01)$ of the IRA piglets.

\section{Discussion}

The positive effect of XOS, but not of SC, on villi length can improve the nutrient uptake from intestine, which could result in improved growth performance. The greater ileal villi in pigs fed XOS may reflect the higher level of energy absorbed in the ileum, as a result of the volatile fatty acids formed by the degradation of XOS. This is in agreement with results obtained by others authors, who reported a positive relationship between dietary oligosaccharide supplementation and higher intestinal villi in piglets (Spencer et al. 1997) and rabbits (Mourão et al., 2006).

According to Buts et al. (1994) saccharomyces have a positive effect on the brush border disaccharidases. Hence, it is possible that these yeasts could stimulate the development of the intestinal villi. Nevertheless, our results failed to confirm this hypothesis, showing no effect of SC on the villus height.

There were anatomical differences in villus and crypts width between anastomosed and intact pigs, as shown in Table 1. These differences are more substancial with long-term protocols, as the functional role of the small intestine is changed to make up for the missing colon. Fuller (1991) showed an increase in the number of goblet cells, hypertrophy of smooth muscles and elongation of the crypts in the small intestine of pigs at 26 weeks after surgery. The IRA piglets had higher jejunal and ileal villi, and longer duodenal and ileal crypts 5 weeks after surgery, as compared with intact animals. Salgado et al. (2002) reported longer duodenal villi and larger jejunal villi in anastomosed pigs and postulated that morphological changes might result from some inflammatory process and a physiological adaptation in order to maintain the role of the colon suppressed by the surgery.
According to Pluske et al. (1996), the maximum digestion and absorption occurs at increasing distances along the crypt:villus axis in the weaned pig. On the other hand, it is known that the weaning induces changes in villus/crypt morphology, but their implications on the absorptive and permeability properties of the small intestine have not been clarified (Lallès et al., 2004). Therefore, it needs to be confirmed if the increase in the crypt:villus axis distances, observed in the case of the weaned IRA piglets, represent or not changes in the absorption capacity of the small intestine.

In conclusion, the XOS but not the SC have little effect on intestinal morphology. The IRA modified the intestinal villus and crypt architecture, but its consequence on the in vivo absorption of nutrients needs to be investigated.

\section{References}

Buts, J.P., Keyser, N., Raedemaker, L., 1994. Saccharomyces boulardii enhances rat intestinal enzyme expression by endoluminal release of polyamines. Pediatr. Res. 36, 522-527.

Castagliulo, I., Lacant, T., Nikulassam, S.T., Pothoulakis, C., 1996. Effects of live Saccharomyces boulardii protease inhibits Clostridium difficile toxin. A effects in the rat ileum. Infect. Immun. 64, 5225-5232.

Collins, M.D., Gibson, G.R., 1999. Probiotics, prebiotics and synbiotics: approaches for modulation the microbial ecology of the gut. Am. J. Clin. Nutr. 69 (Suppl. 1), 1052S.

Ducluzeau, R., Besaada, M., 1982. Effets comparés de l'administration unique ou en continu de Saccharomyces boulardii sur l'établissement de diverses couches de Candida dans le tractus digestif de souris gnotoxeniques. Ann. Microbiol. 133B, 491-501.

Fuller, M.F., 1991. Methodologies for the measurement of digestion. In: Verstegen, M.W.A., Huisman, J., den Hartog, L.A. (Eds.), Proceedings of the 5th International Symposium on Digestive Physiology in Pigs. Pudoc, Wageningen, Netherlands, pp. 273-288.

Lallès, J.P., Boudry, G., Favier, C., Le Floc'H, N., Luron, I., Montagne, L., Oswald, I.P., Pié, S., Piel, C., Sève, B., 2004. Gut function and dysfunction in young pigs: physiology. Anim. Res. 53, 301-316.

Line, J.E., Bailey, J.S., Cox, N.S., Stern, N.J., Tompkins, T., 1998. Effect of yeast supplemented feed on Salmonella and Campylobacter populations in broilers. Poultry Sci. 77, 405-410.

Maxwell, F.J., Duncan, H.S., Hold, G., Stewart, C.S., 2004. Isolation, growth on prebiotics and prebiotic potencial of novel bifidobacteria from pigs. Anaerobe 10, 33-39.

Mourão, J.L., Pinheiro, V., Alves, A., Guedes, C.M., Pinto, L., Saavedra, M.J., Spring, P., Kocher, A., 2006. Effect of mannan oligosaccharides on the performance, intestinal morphology and cecal fermentation of fattening rabbits. Anim. Feed Sci. Technol. $126,107-120$.

Pluske, J.R., Thompson, M.J., Atwood, C.S., Bird, P.H., Williams, L.H., Hartmenn, P.E., 1996. Maintenance of villus height and crypt depth, and enhancement of disaccharide digestion and monosaccharide absorption, in piglets fed on cows' whole milk after weaning. Br. J. Nutr. 76, 409-422.

Salgado, P., Martins, J.M., Carvalho, F., Abreu, M., Freire, J.P.B., Toullec, R., Lalles, J.P., Bento, O., 2002. Component digestibility 
of lupin (Lupinus angustifolius) and pea (Pisum sativum) seeds and effects on the small intestine and body organs in anastomosed and intact growing pigs. Anim. Feed Sci. Technol. 98, 187-201.

SAS, 1989. SAS/STAT Users Guide, Version 6, vol 2, SAS Inst. Inc., Cary, NC, 846.
Spencer, J.D., Touchete, K.J., Liu, H., Alle, G.L., Newcom, M.D., Kerley, M.S., Pace, L.W., 1997. Effect of spry-dried plasma and fructooligosaccharide on nursery performance and small intestinal morphology of weaned pigs. J. Anim. Sci. 75 (S1), 199. 